\title{
Recovery of Phenolic Compounds from Edible Algae Using High Hydrostatic Pressure: An Optimization Approach ${ }^{\dagger}$
}

\author{
Antía G. Pereira 1,2, María Carpena 1, Paula García-Oliveira 1,2, Cecilia Jiménez-López 1,2, \\ Catarina Lourenço-Lopes 1, Anxo Carreira-Casais 1, Javier Echave 1, Paz Otero 1,3, Maria Fraga-Corral 1,2, \\ Patri Gullón 1, Lillian Barros 2, Isabel C.F.R. Ferreira ${ }^{2}$, Miguel A. Prieto ${ }^{1,2, *}$ and Jesus Simal-Gandara ${ }^{1, *}$ \\ 1 Nutrition and Bromatology Group, Department of Analytical and Food Chemistry, \\ Faculty of Food Science and Technology, University of Vigo-Ourense Campus, 32004 Ourense, Spain; \\ antia.gonzalez.pereira@uvigo.es (A.G.P.); maria.carpena.rodriguez@uvigo.es (M.C.); \\ paula.garcia.oliveira@uvigo.es (P.G.-O.); cecilia.jimenez.lopez@uvigo.es (C.J.-L.); c.lopes@uvigo.es (C.L.-L.); \\ anxocc@uvigo.es (A.C.-C.); ecalja@outlook.es (J.E.); pazoterofuertes@gmail.com (P.O.); \\ maria.fraga.corral@hotmail.es (M.F.-C.); patrigullon@gmail.com (P.G.) \\ 2 Centro de Investigação de Montanha (CIMO), Instituto Politécnico de Bragança, Campus de Santa \\ Apolónia, 5300-253 Bragança, Portugal; lillian@ipb.pt (L.B.); iferreira@ipb.pt (I.C.F.R.F.) \\ 3 Department of Pharmacology, Pharmacy and Pharmaceutical Technology, Faculty of Veterinary, \\ University of Santiago of Compostela, 27002 Lugo, Spain \\ * Correspondence: mprieto@uvigo.es (M.A.P.); jsimal@uvigo.es (J.S.-G.) \\ + Presented at the 1st International Electronic Conference on Food Science and Functional Foods, \\ 10-25 November 2020; Available online: https://foods_2020.sciforum.net/.
}

Keywords: algae; bioactive compounds; phenolic compounds; high hydrostatic pressure; extraction optimization

Citation: Pereira, A.G.; Carpena, M.; García-Oliveira, P.; Jiménez-López, C.; Lourenço-Lopes, C.; CarreiraCasais, A.; Echave, J.; Otero, P.; Fraga-Corral, M.; Gullón P.; et al. Recovery of Phenolic Compounds from Edible Algae Using High Hydrostatic Pressure: An Optimization Approach. Proceedings 2021, 70, 110. https://doi.org/10.3390/ foods 2020-07824

Published: 10 November 2020

Publisher's Note: MDPI stays neutral with regard to jurisdictional claims in published maps and institutional affiliations.

Copyright: $@ 2020$ by the authors. Licensee MDPI, Basel, Switzerland. This article is an open access article distributed under the terms and conditions of the Creative Commons Attribution (CC BY) license (http://creativecommons.org/licenses/by/4.0/).
Algae are not only of high ecological, but also of great economic importance. The industrial exploitation of algae has suffered a boom in the last two decades because they are a suitable source of interesting compounds for a number of sectors (agriculture, energy, food science, cosmeceutical, and pharmacology, among others) [1]. Among these compounds, phenolics are gaining attention due to their beneficial health properties that they are thought to confer, as they are usually potent antioxidants, although some of them are also regarded as antimicrobial or anticarcenogenic. Taking into account this information, in this work, high hydrostatic pressure (HHP) was applied to optimize the extraction of phenolic compounds from eight edible algae species (Laminaria spp., Saccharina latissimia, Himanthalia elongate, Undaria pinnatifida, Porphyra spp., Palmaria palmata, Codium spp. and Ulva spp.). The process was optimized by response surface methodology using a five-level central composite design combining the independent variables of processing time $(t, 5-90 \mathrm{~min})$, pressure $(P, 10-600 \mathrm{MPa})$ and solvent $(S, 0 \%-$ $100 \%$ of ethanol $(v / v))$ [2]. The individual and total phenolic compounds and the extraction yield were used as response variables. In general, the optimum extraction conditions for phenolic acids for all eight species analyzed were found at shorter values of $t$, high values of $P$ and high values of $S$. The best results were obtained for Kombu real with a concentration of phenolic compounds of $78.7 \mathrm{mg} / \mathrm{g}$ and a yield of $22 \%$. In conclusion, the present study contributes to the valorization of edible algae species, common in the Northwest region of Spain, by the obtainment of rich extracts in phenolic compounds that potentially can be applied as ingredients in different industrial fields with a promising emerging technology.

Supplementary Materials: The following are available online at https://www.mdpi.com/article/10.3390/foods_2020-07824/s1. 
Institutional Review Board Statement: Not applicable.

Informed Consent Statement: Not applicable.

Data Availability Statement: The data presented in this study are available on request from the corresponding author. The data are not publicly available due to the article is in the process of being published.

Acknowledgments: The research leading to these results received financial support from Programa de Cooperación Interreg V-A España-Portugal (POCTEP) 2014-2020 (projects Ref. 0181_NANOEATERS_01_E and Ref. 0377_IBERPHENOL_6_E) that supports the pre-doctoral grant for C. Jimenez-Lopez; from MICINN supporting the Ramón\&Cajal grant for M.A. Prieto (RYC-201722891) and A. Carreira Casais for his PhD grant (FPU 16/135); from Xunta de Galicia and University of Vigo supporting the post-doctoral grant for M. Fraga-Corral (ED481B-2019/096) and the predoctoral grants for A.G. Pereira (ED481A-2019/0228) and P. García-Oliveira (ED481A-2019/295); from MICINN supporting the Juan de la Cierva post-doctoral grant for Paz Otero (IJCI-2016-27774); from Axudas Conecta Peme (Xunta de Galicia) supporting the IN852A 2018/58 NeuroFood Project and AlgaMar (www.algamar.com) that supports the pre-doctoral grant for C. Lourenço-Lopes; from EcoChestnut Project (Erasmus+ KA202) that supports the work of M. Carpena; from Ibero-American Program on Science and Technology (CYTED-AQUA-CIBUS, P317RT0003); and from Bio Based Industries Joint Undertaking (JU) under grant agreement No 888003 UP4HEALTH Project (H2020BBI-JTI-2019).

\section{References}

1. Zakaria, S.M.; Kamal, S.M.M. Subcritical Water. Food Eng. Rev. 2016, 8, 23-34.

2. Pinela, J.; Prieto, M.A.; Barros, L.; Carvalho, A.M.; Oliveira, M.B.P.P.; Saraiva, J.A.; Ferreira, I.C.F.R. Cold extraction of phenolic compounds from watercress by high hydrostatic pressure: Process modelling and optimization. Sep. Purif. Technol. 2018, 192, 501-512. 